Article

\title{
Deriving a Benefit Transfer Function for Threatened and Endangered Species in Interaction with Their Level of Charisma
}

\author{
Franklin Amuakwa-Mensah * (D), Rebekka Bärenbold ${ }^{(1)}$ and Olivia Riemer ${ }^{(D)}$ \\ Department of Economics, Swedish University of Agricultural Sciences (SLU), Box 7070, 75007 Uppsala, \\ Sweden; r.baerenbold@gmail.com (R.B.); riemer.olivia@hotmail.de (O.R.) \\ * Correspondence: franklin.amuakwa.mensah@slu.se or fam020@hotmail.com; Tel.: +46-722-797-398
}

Received: 30 November 2017; Accepted: 12 February 2018; Published: 23 February 2018

\begin{abstract}
Biodiversity and species conservation are among the most urgent global issues. Both are under serious threat because of human intrusion and as a result, it is likely that present and future projects will affect threatened and endangered species. Thus, it is important to account for these impacts when evaluating and conducting cost and benefit analyses of projects. Due to their public good character and non-tradability, the total economic value of threatened and endangered species cannot be reflected by a market price and therefore, alternative approaches (stated preference method) are needed to determine their monetary value. This paper reviews and compares the valuation literature on threatened and endangered animals and conducts a meta-analysis regression to identify explanatory variables for the variation in willingness to pay for threatened and endangered species. The main findings of the meta-analysis show that the interaction of the level of threat and charisma have a positive effect on willingness to pay. Furthermore, developed countries have a higher willingness to pay compared to developing countries. Similarly, visitors of conservation sites have higher willingness to pay than residents. The provided example of a benefit transfer of the estimated function shows the practicability of our results.
\end{abstract}

Keywords: threatened and endangered species; literature review; meta-analysis; willingness to pay; choice experiment; contingent valuation method

\section{Introduction}

Species extinction and biodiversity loss are a worldwide concern as the global extinction rate increases for more and more species [1]. According to the International Union for Conservation of Nature (IUCN) Red List of threatened species, one in four mammals, one in eight birds and more than $40 \%$ of all amphibians are endangered [2]. The category "threatened" defined by IUCN Red List criteria [3] includes vulnerable, endangered and critically endangered species. They face a high or very high risk of extinction in the wild [3]. This global definition differs from the ones on national level such as the Endangered Species Act (ESA) of 1973 in the United States of America (USA). Most US studies base their classification on the definition by ESA, that distinguishes between the status "extinct", "endangered", "threatened" and "delisted". Thereby endangered species are defined according to ESA [4] as "any species which is in danger of extinction throughout all or a significant portion of its range other than a species of the Class Insecta determined by the Secretary to constitute a pest". Threatened species are specified as "any species which is likely to become an endangered species within the foreseeable future throughout all or a significant portion of its range" [4]. Major threats to biodiversity derive from the current trends in human population growth and consumption as well as the increasing use of natural resources, leading to climate change and global warming, habitat conversion and urbanisation, over-exploitation of natural resources and environmental degradation [5]. 
Since biodiversity is under serious threat as a result of human activities, it is likely that current and future projects will affect threatened and endangered species. This can be in the form of direct impacts intended by conservation programs but also indirect through any other project affecting the habitat of those species. Thus, it is important to account for these impacts when conducting a cost and benefit analysis (CBA) of projects. CBA is a form of economic valuation in which costs and benefits are measured in monetary terms [6]. Often, the economic value of threatened and endangered species cannot be reflected by a market price [7] due to their non-tradability and public good character [8,9]. Their value cannot be derived from observations of individual behaviour in the market [10] and thus, the great challenge is to quantify their costs and benefits in monetary terms.

In the case of threatened and endangered species several types of values, including use value, option value, existence value and bequest value can be associated. According to Wallmo and Lew [11], the value obtained from viewing or photographing these species is considered to be a passive use value. An option value is derived from the preservation of species so that they can possibly be used for future purposes. Benefits in form of existence values can also be gained from the simple knowledge of their existence in their natural habitat without any intentions for future use. Preservation of species for the sake of future generations is an example of a bequest value. Altogether these values form the total economic value (TEV) of threatened and endangered species [12]. Deriving the TEV of each threatened species every time would be costly, time-consuming and beyond the scope of most CBAs and other projects in need of those values. Instead, a common alternative is benefit transfer of values or functions which is a form of secondary research. In the case of value transfer, economic values of the respective species are estimated by applying a single estimate or the average of several estimates from former studies with similar circumstances. For the function transfer, a statistical function from the original site where primary research was conducted is used to calculate the value of a species for a difference site. Values generated through function transfer rather than value transfer are believed to be more accurate because they account for the differences between the studies [13].

In the past, some research has dealt with the analysis of willingness to pay (WTP) for species conservation using a meta-analysis approach. Loomis and White [14] derive a meta-analysis regression for threatened and endangered species based on US studies using contingent valuation method (CVM). This analysis has been updated by Richardson and Loomis [15] adding newer studies and accounting for differences in the values over time as well as the effect of the level of charisma of a species on the WTP. Martín-López et al. [16] carry out a meta-analysis on estimating the effects on WTP for biodiversity conservation including CVM studies that base their WTP question on conservation efforts. More recently, Lew [17] reviews the literature on the economic benefits of threatened, endangered and rare marine species considering studies from different developed countries.

The purpose of this paper is to: (1) review and compare the valuation literature on threatened and endangered animals to provide an overview of past research activities in this field; (2) conduct a meta-analysis regression to identify variables which explain the variation in WTP for threatened and endangered species and (3) illustrate the application of meta-analysis regression functions for benefit transfer by exemplarily estimating the value of a bald eagle population. This analysis adds to the growing literature on non-market valuation on threatened and endangered species. Our paper expands and combines characteristics of previous meta-analyses by enclosing: (1) studies in developed and developing countries in contrast to Richardson and Loomis as well as Loomis and White [14,15]; (2) different classes of species as opposed to Lew [17]; (3) recent studies, covering thus 32 years of research; (4) two forms of the stated preference method (CVM and choice experiment (CE)) and (5) interaction between level of threat and charisma of a species. The results are of relevance since they shed light on societal WTP for threatened and endangered species and provide regression functions for benefit transfer worldwide to value these species.

After giving an overview on the literature of threatened and endangered species the methodology is described. We proceed with the study review, the meta-analysis and a discussion of the results. This is followed by an example of a function benefit transfer and final remarks. 


\section{Literature}

\subsection{Common Methods Used for the Valuation of Threatened and Endangered Species}

The two most common economic valuation methods, CVM and CE, rely on the notion of stated preferences and thus can account for non-use values of threatened and endangered species as compared to the revealed preference approach which is limited to use values [18]. CVM is a theory-based measure of economic value and relies on the concept of maximizing an individual's utility [19]. Therefore, it allows to unveil a population's aggregated WTP for a suggested change in a good. The method uses surveys based on a hypothetical scenario to reveal the value of public goods [20,21]. In the case of threatened and endangered species, the description of the hypothetical market includes provision of information on the species and habitat proposed for preservation, the form and frequency of payment and the question format [22]. CVM differs in the way the question measuring WTP is stated. The three most commonly used are dichotomous choice (DC), open-ended (OE) and payment card (PC) [23]. In the first format, respondents have to accept or reject a randomly assigned monetary amount [24]. In the OE method, individuals are directly asked for the maximum amount they are willing to pay without specifying predetermined values [25]. The PC provides a list of monetary values and respondents are then asked to choose the one closest to their maximum WTP for the scenario presented [26]. Limits which are common to all three response formats of CVM include strategic bias (incentive to misstate WTP for the individual's own gain), hypothetical bias (due to the made-up setting), framing effects caused by the survey instrument and yes-saying (acquiescence bias) which can lead to distorted estimates $[27,28]$.

The approach of CE is based on the combination of Lancaster's characteristics theory of value [29] and the random utility theory [30,31]. Respondents are assumed to maximize their utility through the choice they make in a given situation [32]. In practice, individuals are presented with a choice set and are asked to repeatedly choose between bundles of attributes[18] including the costs of the conservation program. Therefore, when the individual makes a choice there is an implicit trade-off between the different levels of the attributes [33] (e.g., conservation success rate, habitat improvement, population size, method of funding or chance of sighting the animal). Even though there are possible advantages with CE (e.g., avoiding the yay-saying problem, experimental design) compared to CVM, fewer studies used this approach to measure environmental values [18,33]. However, there is also some criticism regarding the $\mathrm{CE}$ technique including issues with the internal consistency of choices such as the extent to which strictly-dominated options are chosen [34] or whether participants always choose the same option when they are repeatedly presented with the same choice set [35].

\subsection{Findings in the Literature on the Determinants of WTP}

There seems to be a disparity of people's WTP for different classes of species. Large vertebrates, especially mammals and birds, receive higher WTP [36,37]. The study by White et al. [38] reveals a higher WTP for marine animals compared to terrestrial species. The results of Yao et al. [39] suggest that the WTP for birds is higher than for non-bird species. Ressurreiçao et al. [40] found that preferences for marine taxa deviate across countries and thus are subject to cultural differences. According to them, the WTP approach is likely to reflect values such as ethical and moral values, knowledge and tradition. A former study by Kotchen and Reiling [41] has found that prior knowledge has a positive effect on WTP. Further, environmental attitudes and awareness [41,42] as well as professional occupation [40] influence people's WTP. With increasing income, the WTP for the conservation of threatened and endangered species rises [24]. A common driver behind people's WTP for the conservation of a species is "charisma". The expression "charismatic species" refers to species that are familiar, aesthetic organisms and thus have popular appeal and inspire public affection [43]. In addition to that, they are also easily recognisable and stated by name (e.g., elephant, panda, tiger). Further, they can be related to a specific geographical location or habitat (e.g., African savannahs, Chinese bamboo forests) [44] and are used to draw attention on conservation campaigns [45]. The aggregate evidence by the literature 
shows that overall, charismatic species are more likely to be preserved and receive a higher stated WTP by respondents $[15,46,47]$. Although Tisdell and Nantha [48] found that the likeability of a species influences the WTP to conserve the animal, people's perception of the degree of endangerment seems to be the more important factor affecting WTP. According to Metrick and Weitzman [47], government spending on the conservation of a species is also driven by charismatic and non-charismatic attributes. They mention especially factors such as physical size and visceral characteristics to be of importance when deciding on how much a government spends for a species' conservation. Factors which are considered to be more on the scientific spectrum such as endangerment or uniqueness were less important in the spending stage of the decision process. On the individual consumer level, similar conclusions have been drawn. There has been found a strong correlation between an individual's WTP and its attitudes towards a species and thus scientific reasons such as the ecological role of the species seem to be of lesser importance [49]. Colléony et al. [49] argue that a more endangered species is not likelier to get a higher donation by people. However, several studies [48,50-52] found the opposite effect concluding that the degree of endangerment has a high influence on people's WTP.

\section{Methods}

\subsection{Literature Search and Study Collection}

The databases Google Scholar, Web of Science and Scopus were used to find valuation studies concerning threatened and endangered species using a range of different keywords. Table 1 contains the applied keywords and the results of our literature search.

Table 1. Number of unique hits by keywords and database (as of 1 February 2018).

\begin{tabular}{|c|c|c|c|c|c|c|}
\hline & & & Database & & & \\
\hline & Google Scholar & & Scopus & & & Web of Science \\
\hline $\begin{array}{l}\text { Keywords } \\
\text { Used }\end{array}$ & $\begin{array}{l}\text { Any } \\
\text { Where }\end{array}$ & $\begin{array}{l}\text { In } \\
\text { Title }\end{array}$ & $\begin{array}{l}\text { Title, } \\
\text { Keyword, } \\
\text { Abstract }\end{array}$ & Title & Keyword & Topic \\
\hline $\begin{array}{l}\text { "threatened species" } \\
\text { and "economic valuation" }\end{array}$ & 2560 & 23 & 5 & 0 & 0 & 14 \\
\hline $\begin{array}{l}\text { "endangered species" } \\
\text { and "economic valuation" }\end{array}$ & 6760 & 67 & 19 & 1 & 7 & 24 \\
\hline $\begin{array}{l}\text { "species valuation" } \\
\text { and "economic" }\end{array}$ & 488 & 13 & 3 & 0 & 0 & 3 \\
\hline $\begin{array}{l}\text { "wildlife valuation" } \\
\text { and "economic" }\end{array}$ & 494 & 32 & 4 & 0 & 0 & 6 \\
\hline $\begin{array}{l}\text { "economic valuation" } \\
\text { and "species" }\end{array}$ & 25,900 & 920 & 182 & 3 & 27 & 311 \\
\hline $\begin{array}{l}\text { "threatened species valuation" } \\
\text { and "economic" }\end{array}$ & 2 & 1 & 0 & 0 & 0 & 0 \\
\hline $\begin{array}{l}\text { "endangered species valuation" } \\
\text { and "economic" }\end{array}$ & 291 & 4 & 0 & 0 & 0 & 0 \\
\hline
\end{tabular}

In addition to the studies found through the three databases we also obtained relevant work from citation in other papers and previous meta-analyses as well as from reviews in the field [14-17,53]. The studies were further scanned and selected based on two criteria: the species being valued had to be (a) an animal and (b) threatened or endangered according to our definition. That is, the animal was listed as "threatened" or "endangered" in the ESA or as "vulnerable", "endangered" or "critically endangered" by the IUCN Red List at the time of the valuation. All in all, 87 studies were found to match the requirements. However, among these 87 studies some measured use-values rather than non-use values or did not include all the information we needed regarding the sample, study method, 
payment vehicle, frequency of payment and WTP value. After dropping these studies, we obtained a total of 53 studies which were closely related to the aim of our study and thus, were used for the literature review. A summary of the relevant studies can be found in Table S1 in the supplementary documents. As this paper considers studies that take place in different countries and years the values of the original paper sources differ in terms of currency and purchasing power. Therefore, all WTP values were converted to US dollars to the base year of 2015 using the US-Consumer Price Index of urban consumers for comparability [54]. However, for seven studies [48,55-59] the year of conduction was not available and thus, we assumed a study year that was most likely. The year 2015 has been chosen as the base year since it is the survey date of the most recent study included in the analysis.

\subsection{Methodology of Review}

Firstly, the selected studies are compared based on the country of the study site and the type of animal being valued. Furthermore, this paper investigates the different valuation methods based on the following criteria: The studies are distinguished regarding the methodology used to elicit and derive the mean WTP and further, common explanatory variables for the regression model are identified. We compare the various scenarios as well as form and frequency of payment vehicles used by the different studies. Afterwards, the assumptions about changes caused by the conservation project and the project's likelihood of success are contrasted. Attention is also payed to the choice of the sample approach and the survey instrument. Moreover, the difficulties faced by the different studies and the way they deal with possible biases are examined.

\subsection{Categorisation of Species}

As this paper emphasizes the interaction between charisma and level of threat of a species and its effect on WTP, the included species have been assigned to one of the four categories: threatened with low charisma, threatened with high charisma, endangered with low charisma and endangered with high charisma. These variables have been chosen since empirical evidence suggests that WTP is significantly affected by the degree of charisma and threat. Non-charismatic and less appealing species are assigned to the low-charisma category, whereas flagship and well-known aesthetic species are part of the highly charismatic group. The species are assigned to one of the two categories based on the information provided in the study regarding the prior knowledge of the respondents, the likeability and aesthetic appearance or the direct reference to the level of charisma. If this information was not available it was taken from other literature. The list of references for the charisma categorisation is provided in Document S2 in the supplementary documents. The studies have referred to the degree of endangerment in different ways. Most US studies define the species based on the categories of ESA. Other papers refer to the categorisation as threatened or endangered based on regulations by the European Union [58], the number of species, the rate of habitat disruption or the number of countries inhabiting the respective species. Whenever the listing reference was not clear, the status of the respective species has been matched to the one of the IUCN Red List at the time. On this basis, all species in this paper have been categorised as "threatened" if they have been listed as "threatened" in the ESA or as "vulnerable" according to IUCN Red List. The category "endangered" includes species that have been listed as "endangered" according to ESA or are indicated as "endangered" or "critically endangered" on the IUCN Red List. For further detail on the categorisation of the species see Appendix Table A1.

\subsection{Methodology of Meta-Analysis}

Following the work of Richardson and Loomis [15], a meta-analysis is undertaken to examine how WTP for threatened and endangered species obtained from several studies is explained by various attributes of the studies (that is, response rate, method of analysis, sample size, country, etc.). In total 52 studies with about 85 WTP estimates were sourced and used for the meta-analysis (however, we excluded the study by Kontogianni et al. [60] because it distorted the results). As discussed earlier, 
the novelty of our study is attributed to the fact that it considers studies from both developed and developing countries unlike the study by Richardson and Loomis [15] which only focused on studies in the USA. Moreover, our study considers how the interaction between the level of threat and the level charisma of species affect the WTP. Also, we considered studies published in recent times with the latest being 2017. The empirical model for the meta-analysis is specified as:

$$
\begin{aligned}
\ln W T P(2015 \$)= & b_{0}+b_{1} \text { lnresponserate } \pm b_{2} \text { lnsamplesize } \pm b_{3} \text { Studyyear }-b_{4} \text { Developingcountry } \\
& +b_{5} \text { Survey format } \pm b_{6} \text { Paymentvehic } \pm b_{7} \text { Paymentfreq } \\
& +b_{8} \text { Threatened } \# \text { Charismalevel } \pm b_{9} \text { Class }-b_{10} \text { Resident }+b_{11} \text { Method }+\epsilon
\end{aligned}
$$

where $\ln W T P(2015 \$)$ is the natural log of the 2015 base year value of WTP, Inresponserate is natural $\log$ of the response rate of the survey, Insamplesize is the natural log of the sample size for a particular study, Studyyear is the year in which the study took place, Developingcountry represents a dummy variable which takes the value of 1 if the study area is a developing country and 0 otherwise. The survey format is represented by Survey format, a dummy variable coded 1 if the questionnaire is administered by face-to-face and 0 otherwise. Paymentvehic is a categorical variable representing the payment vehicle and it comprises of tax, bills, membership fees, trust fund and an unspecified means. Because of the issue of dummy variable trap, tax is used as a reference category (that is, omitted). The payment frequency is represented by a categorical variable, Paymentfreq and it comprises of the following categories: annual, monthly, once and per visit. The category "annual" is used as the reference group. An interaction between the level of threat and the level of charisma of species is introduced in the model as Threatened\#Charismalevel. The level of threat of the species is coded as 1 when the species is threatened and 0 when it is endangered. High charismatic species are coded 1 and 0 otherwise. The variable, Class shows the species class, that is, whether the species belong to the following class: bird, fish, invertebrate, marine mammal, terrestrial mammal and reptile. Bird is used as the reference category in the estimations. The respondent type is represented by a dummy variable (Resident) which is 1 when the respondents in the study are residents and 0 otherwise. Method shows whether CVM or CE or a hybrid of the two is used in the study. CVM is used as a reference category in the analysis.

From Equation (1), the sign in front of each variable is the expected sign or the hypothesized relationship between the variable and WTP based on previous studies. High response rate is expected to have negative effect on WTP as suggested by Richardson and Loomis [15] and Boyle et al. [61]. WTP estimates in developing countries for threatened and endangered species are expected to be lower than those in developed countries. This is because developed countries have relatively high income than developing countries. It is expected that respondents tend to give higher WTP values when questionnaires are administered face-to-face than when it administered by other means. As the level of threat and level of charisma of a species increases individuals tend to offer higher WTP values. The hypothesized sign on the species class variable might differ depending on species classification, however, birds generally have higher WTP compared to other species. This assertion is based on previous studies (see Richardson and Loomis [15]; Loomis and White [14]; Yao et al. [39]). Surveys using visitors as sample are expected to have a higher WTP values for threatened and endangered species than residents of the study area. This is because visitors most at times have use as well as non-use values for the species [15]. Based on previous studies we expect WTP estimates for CEs to be higher than that of CVM. Richardson and Loomis [15] in their meta-analysis found a significant positive effect of CE on WTP relative to CVM. The sample size, year of the study, payment vehicle and frequency of payment are hypothesized to have an ambiguous effect on WTP.

A multicollinearity test is carried out using simple correlation test among the explanatory variables and we found low correlation among the variables. In order to be more confident in our multicollinearity test, variance inflation factor (VIF) is carried out to check whether or not multicollinearity is severe. The results show low level of multicollinearity (see Appendix Table A2). A step-wise procedure is used in estimating Equation (1) to ascertain a best-fit model for benefit 
transfer purpose. We first estimate the full model in Equation (1) to avert the problem of omitted variable bias. A sequential elimination of insignificant variables is followed until a best fit model is obtained for the benefit transfer. The model with the highest adjusted R-squared and the lowest Akaike information criterion (AIC) and Bayesian information criterion (BIC) is chosen.

\section{Results}

\subsection{Review of Valuation Studies}

The 53 studies with 56 surveys can be distinguished according to the geographical location of the study site. 11 surveys (19.7\%) were conducted in developing countries and 45 surveys $(80.3 \%)$ were carried out in developed countries. As it can be seen in Table 2, $23(41.1 \%)$ of the surveys are located in the USA.

Table 2. Geographical distribution of studies.

\begin{tabular}{lc}
\hline $\begin{array}{l}\text { Developed } \\
\text { Countries }\end{array}$ & $\begin{array}{c}\text { Number } \\
\text { of Studies }\end{array}$ \\
\hline Australia & 6 \\
Canada & 3 \\
China & 4 \\
Greece & 3 \\
Italy & 1 \\
New Zealand & 1 \\
South Korea & 3 \\
United Kingdom & 1 \\
United States of America & 23 \\
\hline Subtotal & 45 \\
\hline Developing & \\
Countries & \\
\hline Congo & 1 \\
India & 1 \\
Malaysia & 1 \\
Nepal & 1 \\
Philippines & 2 \\
Sri Lanka & 2 \\
Thailand & 1 \\
Vietnam & 2 \\
\hline Subtotal & 11 \\
\hline Total & 56 \\
\hline
\end{tabular}

In total, this review covers 92 valued species of which $37(40.2 \%)$ are marine or terrestrial mammals, 19 birds (20.7\%), 19 fishes (20.7\%), four invertebrates (4.4\%), and 13 reptiles (14.1\%). As it has already been noticed by Decker and Watson [55] most studies were conducted on charismatic rather than non-charismatic species.

The analysed valuation studies can further be distinguished by their study method. In total, we reviewed 43 CVM studies, nine CE studies and one hybrid. Studies applying CVM use different WTP value elicitation formats. Five studies apply multiple formats $[23,59,62-64]$ whereas all other studies only use one. The most frequently used format is the DC approach $[24,26,42,56,57,64-79]$. Instead of only allowing for yes or no answers, Loomis and Ekstrand [26] expand this method by accounting for the degree of certainty in the responses (multiple-bounded DC method). In the DC approach, the proposed monetary value for the species, the study-specific variables as well as socioeconomic variables are used to formulate a probabilistic model from which the expected WTP values are derived. For these studies, either a logit or probit model is applied and afterwards the 
mean WTP is calculated by using a maximum likelihood approach in most cases. An exception is e.g., the study by Giraud et al. [80] which uses the "grand constant" to calculate the mean WTP. Fewer studies elicit WTP by using the OE approach with follow-up questions and taking the average over the stated WTP values [25,60,81,82], using a mixture model [83] or applying a tobit model [64,84] to estimate mean WTP. Other studies use a PC to elicit WTP and estimate mean WTP by applying a simple approach of taking the average [10,85], implementing a tobit model [86] or using the mathematical expectation formula for discrete variables [87]. Additionally, there is one study where the response format could not be identified [88].

Besides estimating the mean WTP, most studies analyse the variance in WTP explained by different independent variables. Common variables included in the regression analysis are bid value, age, gender, household size, income, education, membership of an environmental association or attitudes towards the environment as well as awareness of the conservation issue.

A range of different scenarios have been assumed across the studies. Whereas some studies examine one scenario, others ask about the WTP for several scenarios. A popular assumption for the hypothetical market is the conservation of the addressed species in form of habitat preservation and population growth. Less common scenarios are the change in use values by allowing or restricting fishing $[66,70,81]$, chance of sighting the species $[39,89]$, raising awareness for the conservation needs [25,76], support of research [10,48,70,76,82,90], a project of reintroducing the species [87], a management program to reduce human-species conflicts [62] and compensation for damages caused directly by the species $[56,69,83]$ or due to the financial losses caused by conservation efforts [75]. In the case of the use of multiple scenarios, different WTP values are elicited for the variation in stock size [66,81], type of respondents (residents and/ or visitors) $[24,70,75,81,86]$ and chance of survival [23,91]. While most studies do not refer to the likelihood of success of the preservation programs, a few surveys include the confidence in the program in information provided to the respondents. For example, Giraud et al. [70] and Reaves et al. [23] point out that the success of the conservation project is not guaranteed. Another exceptional case is the study by Jin et al. [73] which elicits the WTP for marine turtles across different Asian countries in contrast to all the other studies which measure WTP within a single country.

The nine CE studies [11,39,55,58,89,92-95] differ with regards to the attributes included in the choice sets and slight differences occur with respect to the regression model applied. All CE studies have two alternatives besides the status quo or the option of doing nothing. Wallmo and Lew [11,92,95] assume an improvement of the ESA list status and only use the threatened and endangered species as well as costs of the conservation program as attributes. Instead, Decker and Watson [55] and Rudd [93] include additional attributes, such as population size, ecological quality, public access, method of funding and probability of success. Mean WTP is estimated by using a mixed logit model [55,58], rank-ordered random parameter logit model (RPL) [11,39,89,92,95], a multinomial logit model [94], a 9-class latent class (LC) logit model [93] or a WTP-space model [58].

The reviewed valuation studies further vary according to the payment vehicle described. The most common form of payment vehicle is taxes but the way in which they are collected differs (annual payment or one-time payment). Alternative payment vehicles are voluntary donations, contribution to trust funds, membership fees and higher prices for goods and services. An exception is the study by Ninan and Sathyapalan [96], who measure the WTP of the respondents for Asian elephants in terms of foregone income by volunteering for the conservation program. Differences also occur in terms of the frequency of payment. Some surveys asked for annual or monthly payments, whereas other studies derive mean WTP values based on one-time payments or contribution per visit. The comparison of the studies reveals that six different survey instruments have been used to approach respondents: face-to-face interviews and questionnaires, mail and online surveys, telephone interviews or drop-off surveys.

Common difficulties appear when estimating the value of non-tradeable and public goods which reduce the validity of the study results. Some study results have little informative value due to a 
small sample size and a non-representative character of the sample. Other analyses suffered from low response rates depending on the choice of survey instrument which allowed for self-selection and thus led to overestimated WTP values. Different techniques have been used to minimize hypothetical bias. Six studies $[39,57,73,74,76,97]$ included cheap talk scripts to remind respondents about the importance of a real vote although it is set in a hypothetical scenario. Another technique used by several studies is the certainty scale where respondents were asked about their confidence in their answers of the stated amount of WTP. All uncertain yes votes were reclassified to no votes to allow for more realistic and conservative measures of economic values. To avoid strategic and hypothetical bias, Kim et al. [75] try to create a real setting by including a follow-up question after the WTP question asking about the preferred method of payment for the stated amount. A special issue when valuing wildlife is that although they are embedded into an ecosystem people state their WTP without considering the ecological role of the species [98]. White et al. [77] observed that mean WTP does not increase with the number of species being conserved and that people rather state a symbolic than additive value. Therefore, the embedding effect can lead to less accurate WTP estimates in such that studies valuing species in an isolated context separated from the ecosystem yield higher WTP values than those which place them in a broader framework [98]. Consequently, the WTP values have to be taken with caution.

\subsection{Meta-Analysis}

Table 3 shows the estimations of the WTP models. Model 1 of the table represents the full model in Equation (1). For models 2-4, we successively delete the insignificant variables in order to improve the model fitness for the purpose of benefit transfer estimations. From the adjusted R-squared, it is evident that the model improves as the insignificant variables are sequentially removed from the model. In addition, the AIC and BIC reduces as we eliminate the insignificant variables and as such we chose the model with the lowest AIC and BIC. Generally, the results show that WTP is significantly affected by response rate, sample size, the level of threat and charisma of species, the country in which the survey is conducted, payment vehicle, frequency of payment, species class and the type of respondents. Whereas an increase in the response rate reduces the WTP values, an increase in the sample size increases the WTP values. The negative effect of response rate on WTP is similar to that of Richardson and Loomis [15] and also confirms the assertion by Boyle et al. [61]. Threatened species with low charisma are observed to have lower WTP values compared to those in other groups (that is, endangered with low charisma, endangered with high charisma and threatened with high charisma). Thus, species in any other groups have significantly higher WTP values than those which are threatened and have low charisma. A careful observation of the coefficients of endangered species with high charisma and threatened species with high charisma in model 4 shows no significant difference between their WTP values. This assertion is confirmed by a formal test of equality between the two coefficients where we fail to reject the null hypothesis of equality (that is, $\mathrm{F}(1,61)=0.08$. Prob $>\mathrm{F}=0.772$ ).

As expected, we find a significant difference between WTP values for developing and developed countries in the case of threatened and endangered species. The WTP values for threatened and endangered species are low in developing countries compared to their developed counterpart. This is because income levels in developed countries are relatively higher than developing countries. Relative to taxes, payment vehicles such as bills and trust fund have lower WTP values. The high WTP values when taxes are used as the payment vehicle may be due to the enforceability of taxes. The results also show that annual payments are significantly higher than monthly payments. Compared to fish, terrestrial mammal and reptile, WTP values for endangered and threatened birds are significantly higher. These findings corroborate that of Richardson and Loomis [15], Loomis and White [14] and Yao et al. [39]. From model 4, the relative WTP value between birds and the other species class has fish as the highest, followed by reptile and terrestrial mammal. In relation to how WTP values for endangered and threatened species vary for respondent types, findings from model 4 show a significant difference between when visitors constitute the sample frame and when residents are considered. 
As expected visitors are willing to pay higher values for threatened and endangered species compared to residents since visitors most at times have use as well as non-values for the species [15].

Table 3. Full and reduced form WTP models.

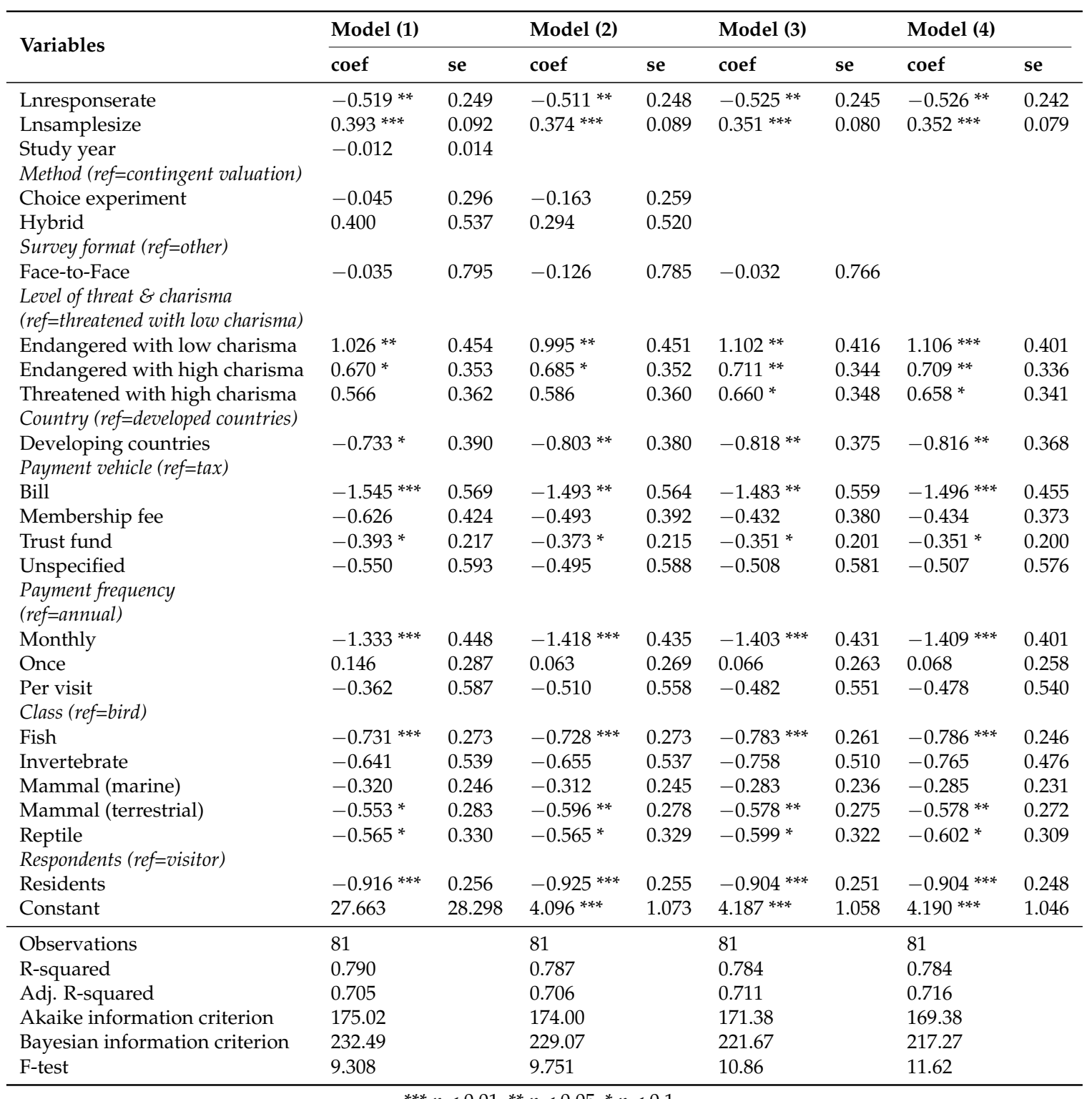

\subsection{Benefit Transfer Example for Threatened and Endangered Species}

As mentioned earlier the purpose of the meta-analysis in this study is to enable us to predict WTP values for threatened and endangered species taking into account their charisma level. Since model 4 in Table 3 is relatively the best fit based on the data, the meta-analysis function is programmed to aid us with the benefit transfer. The reduced form model in Table 3 can be expressed as:

$$
\begin{aligned}
\ln W T P(2015 \$)= & 4.190-0.526 \text { lnresponserate }+0.352 \text { lnsamplesize }-0.818 \text { Developingcountry } \\
& +1.106 \text { Endang } * \text { LowCharisma }+0.709 \text { Endang } * \text { HighCharisma } \\
& +0.658 \text { Threat } * \text { HighCharisma }-1.496 \text { Bill }-0.351 \text { TrustFund } \\
& -1.409 \text { Monthly }-0.904 \text { Resident }-0.786 \text { Fish }-0.578 \text { Mammal(terrest. }) \\
& -0.602 \text { Reptile }
\end{aligned}
$$


To obtain the WTP value for any species we first would have to plug in the sample means values for the methodological variables (that is, response rate and the sample size). From our data the sample mean for the response rate and sample size variables are $61.03 \%$ and 1713 respondents respectively. If one wants to predict the WTP value for a charismatic endangered bald eagle population of a visitor in a developed country who is willing to make an annual contribution to a trust fund, the computation is shown in equation 3 below:

$$
\begin{aligned}
\ln W T P(2015 \$)= & 4.190-0.526 \ln (61.03)+0.352 \ln (1713)-0.818(0)+1.106(0)+0.709(1)+0.658(0) \\
& -1.496(0)-0.351(1)-1.409(0)-0.904(0)-0.786(0)-0.578(0)-0.602(0)
\end{aligned}
$$

Equation (3) results in a TEV of about $\$ 149.37$ per household. In a developing country context, the TEV for the same example will be $\$ 66.05$ per household. In a case where residents are considered, the TEV for developed and developing countries will be $\$ 60.49$ and $\$ 26.75$ per household respectively. These estimates can be aggregated for the entire population if one has information on the number of households. For instance, if the resident population for both the developed and developing countries is one million, then the TEV for the charismatic endangered bald eagle population will be $\$ 60.49$ million and $\$ 26.75$ million for the developed and developing country respectively.

It should be noted that in a situation where this eagle in question is threatened and has low charisma, the TEV will be lower. Thus, for visitors and residents in a developed country this value will be $\$ 73.51$ and $\$ 29.77$ respectively. The corresponding values for a developing country are $\$ 32.51$ for visitors and $\$ 13.16$ for residents. This illustration confirms the notion that the level of threat and the level of charisma of a species has significant effect on its TEV. This value increases with the levels of charisma and threat of the species. Taxes as a payment vehicle is observed to yield the highest WTP value for threatened and endangered species. Table 4 shows an illustration of the WTP values for the charismatic endangered bald eagle by comparing tax and trust fund as payment vehicles. As expected, the WTP values are high when taxation is the payment vehicle compared to other forms of payment vehicles. The effectiveness of tax to yield the highest WTP is due to its enforceability.

Table 4. WTP for charismatic endangered bald eagle (tax vs. trust fund).

\begin{tabular}{llcc}
\hline Country & Payer & Trust Fund (\$) & Tax (\$) \\
\hline Developed & Visitor & 149.37 & 212.18 \\
& Resident & 60.49 & 85.92 \\
\hline Developing & Visitor & 66.05 & 93.82 \\
& Resident & 26.75 & 37.99 \\
\hline
\end{tabular}

Source: Authors' computation.

\section{Conclusions}

The purpose of this paper has been threefold, that is, to review and compare the valuation literature for threatened and endangered animals, conduct a meta-analysis regression to identify variables which explain the variation in WTP for threatened and endangered species and how the results from the meta-analysis can be used for benefit transfer purpose. Most studies reviewed made use of CVM relative to CE to estimate WTP values for threatened and endangered species. The CVM studies differ in terms of the hypothetical market with regards to the scenario and the payment vehicle used. The most common form of payment vehicle is taxes but the way in which they are collected differs (annual payment or one-time payment). CE studies were observed to differ with respect to the choice sets and the attributes considered. The review also found that some study results have little informative value due to a small sample size and a non-representative character of the sample. Also, other studies suffered from low response rates depending on the choice of survey instrument allowing for self-selection and thus leading to overestimated WTP values. 
The meta-analysis showed that changes in WTP for threatened and endangered species are significantly explained by the response rate, sample size, payment frequency and payment vehicle. In addition, findings suggested that WTP for threatened and endangered species in developed countries is significantly higher than developing countries. Moreover, visitors were found to have higher WTP values than residents. As expected, WTP increases with the level of threat and charisma of species. Monthly payment was found to be significantly lower than annual payments, and payment via taxes is relatively higher than those by bills and trust fund. Based on our meta-analysis regression function, we illustrated how TEVs for threatened and endangered species can be derived through the benefit transfer concept. From the benefit transfer illustration, one does not need advance training or knowledge in economics or quantitative methods to derive the TEVs for any threatened and endangered species. Although prediction from our model is not $100 \%$ accurate given the adjusted R-squared of about 0.716, it however provides sufficient and relevant information on the TEV of threatened and endangered species given the huge cost (in terms of time and money) in conducting a survey.

Our findings have several policy implications. Although tax as a payment vehicle yields the highest WTP due to its enforceability, policies should be targeted on educating the population about threatened and endangered species. Most people are unaware of the various plant and animal species existing in their environments and the rate at which these species are depleting due to human activities. Given the extinct knowledge about these species, the WTP to protect them is very low, especially in developing countries. In addition, policies and reforms that aim at boosting economic growth and providing alternative source of livelihood in developing countries are essential. Most people in developing countries depend directly on nature as their source of livelihood and their actions may cause a threat and as such endanger species. These policies will reduce the over-reliance on nature and increase the WTP for threatened and endangered species.

Supplementary Materials: The following are available online at www.mdpi.com/2076-3298/5/2/31/s1, Table S1: Summary of studies, Document S2: List of references for charisma categorisation.

Acknowledgments: We thank the three anonymous reviewers for their constructive suggestions and comments which have improved the work.

Author Contributions: O.R. and R.B. originally conceived the idea of the manuscript. They both searched for the articles, analysed the literature and provided the relevant data for the meta-analysis. F.A.-M. contributed by estimating and analysing the results from the meta-analysis and benefit transfer. All authors discussed the results and contributed to the final manuscript.

Conflicts of Interest: The authors declare no conflict of interest.

\section{Abbreviations}

The following abbreviations are used in this manuscript:

$\begin{array}{ll}\text { AIC } & \text { Akaike information criterion } \\ \text { BIC } & \text { Bayesian information criterion } \\ \text { CBA } & \text { Cost and benefit analysis } \\ \text { CE } & \text { Choice experiment } \\ \text { CVM } & \text { Contingent valuation method } \\ \text { DC } & \text { Dichotomous choice } \\ \text { ESA } & \text { Endangered Species Act } \\ \text { IUCN } & \text { International Union for Conservation of Nature } \\ \text { OE } & \text { Open-ended } \\ \text { PC } & \text { Payment card } \\ \text { TEV } & \text { Total economic value } \\ \text { USA } & \text { United States of America } \\ \text { WTP } & \text { Willingness to pay }\end{array}$




\section{Appendix A. Categorisation of Species Based on the Level of Threat and Charisma}

Table A1. Categorisation of species based on the level of threat and charisma.

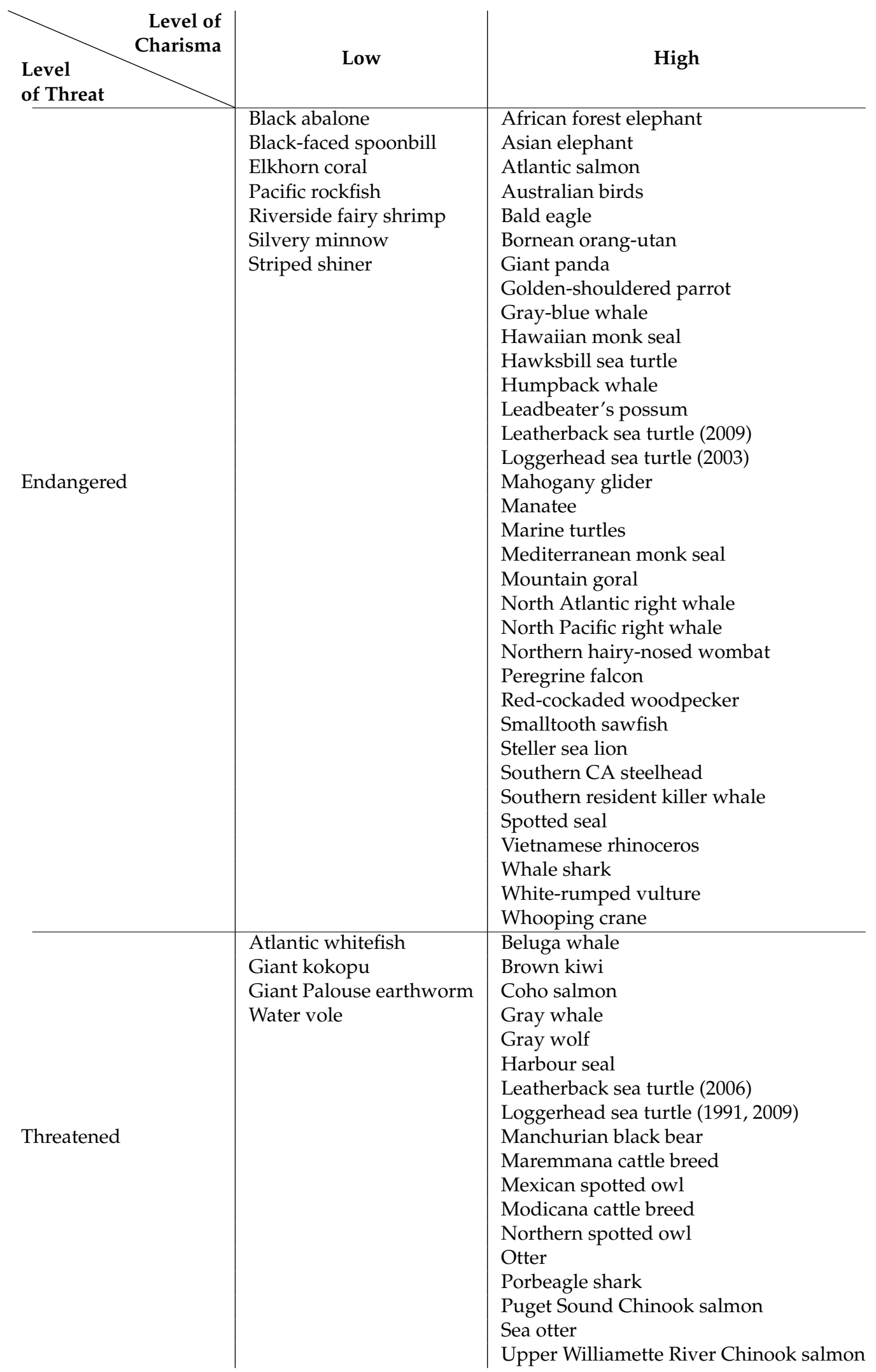




\section{Appendix B. Variance Inflation Factor (VIF) for Model 4}

Table A2. Variance inflation factor (VIF) for model 4.

\begin{tabular}{lll}
\hline Variable & VIF & 1/VIF \\
\hline Endangered with high charisma & 5.82 & 0.171923 \\
Threatened with high charisma & 4.85 & 0.206191 \\
Endangered with low charisma & 2.68 & 0.372664 \\
Lnresponserate & 2.44 & 0.410102 \\
Lnsamplesize & 2.42 & 0.413985 \\
Monthly & 2.32 & 0.43036 \\
Fish & 2.28 & 0.437663 \\
Invertebrate & 2.25 & 0.445233 \\
Mammal (terrestrial) & 2.11 & 0.474599 \\
Bill & 2.05 & 0.488542 \\
Mammal (marine) & 2.02 & 0.495772 \\
Once & 2.01 & 0.496659 \\
Trust fund & 2.01 & 0.498053 \\
Developing country & 1.96 & 0.509929 \\
Resident & 1.75 & 0.571301 \\
Membership fee & 1.7 & 0.587464 \\
Unspecified & 1.69 & 0.593328 \\
Reptile & 1.59 & 0.630828 \\
Per visit & 1.48 & 0.674639 \\
\hline Mean VIF & 2.39 & \\
\hline \multicolumn{2}{c}{ VIF = Variance inflation factor. } &
\end{tabular}

\section{References}

1. Flather, C.H.; Knowles, M.S.; Kendall, I.A. Threatened and endangered species geography. BioScience 1998, $48,365-376$.

2. IUCN. The IUCN Red List of Threatened Species. Available online: https://cmsdocs.s3.amazonaws.com/ keydocuments/IUCN_Red_List_Brochure_2015_LOW.pdf (accessed on 29 November 2017).

3. IUCN. Red List Categories and Criteria Version 3.1. Available online: http://www.iucnredlist.org/technicaldocuments/categories-and-criteria/2001-categories-criteria (accessed on 29 November 2017).

4. Department of the interior, U.S. Fish and Wildlfe Service. Endangered Species Act of 1973. Available online: https: / / www.fws.gov / endangered/esa-library/pdf/ESAall.pdf (accessed on 29 November 2017).

5. Convention on Biological Diversity. Major Threats. Available online: http://www.biodiv.be/biodiversity/ threats (accessed on 29 November 2017).

6. Ackerman, F.; Heinzerling, L. Pricing the priceless: Cost-benefit analysis of environmental protection. Univ. Pa. Law Rev. 2002, 150, 1553-1584.

7. Jakobsson, K.M.; Dragun, A.K. Contingent Valuation and Endangered Species: Methodological Issues and Applications; Edward Elgar Publishing: Cheltenham, UK, 1996.

8. Bishop, R.C. Endangered species and uncertainty: The economics of a safe minimum standard. Am. J. Agric. Econ. 1978, 60, 10-18.

9. Hanemann, W.M. Valuing the environment through contingent valuation. J. Econ. Perspect. 1994, 8, $19-43$.

10. Stanley, D.L. Local Perception of Public Goods: Recent Assessments of Willingness-to-pay for Endangered Species. Contemp. Econ. Policy 2005, 23, 165-179.

11. Wallmo, K.; Lew, D.K. A comparison of regional and national values for recovering threatened and endangered marine species in the United States. J. Environ. Manag. 2016, 179, 38-46.

12. Randall, A.; Stoll, J.R. Existence value in a total valuation framework. In Managing Air Quality and Scenic Resources at National Parks and Wilderness Areas; Westview Press: Boulder, CO, USA, 1983; pp. 265-274.

13. Rosenberger, R.S.; Loomis, J.B. Benefit transfer. In A Primer on Nonmarket Valuation; Springer: Dordrecht, The Netherlands, 2003; pp. 445-482. 
14. Loomis, J.B.; White, D.S. Economic benefits of rare and endangered species: Summary and meta-analysis. Ecol. Econ. 1996, 18, 197-206.

15. Richardson, L.; Loomis, J. The total economic value of threatened, endangered and rare species: An updated meta-analysis. Ecol. Econ. 2009, 68, 1535-1548.

16. Martínlópez, B.; Montes, C.; Benayas, J. Economic valuation of biodiversity conservation: The meaning of numbers. Conserv. Biol. 2008, 22, 624-635.

17. Lew, D.K. Willingness to pay for threatened and endangered marine species: A review of the literature and prospects for policy use. Front. Mar. Sci. 2015, 2, 96, doi:10.3389/fmars.2015.00096.

18. Adamowicz, W.; Boxall, P.; Williams, M.; Louviere, J. Stated preference approaches for measuring passive use values: Choice experiments and contingent valuation. Am. J. Agric. Econ. 1998, 80, 64-75.

19. Hanley, N.; MacMillan, D.; Wright, R.E.; Bullock, C.; Simpson, I.; Parsisson, D.; Crabtree, B. Contingent valuation versus choice experiments: Estimating the benefits of environmentally sensitive areas in Scotland. J. Agric. Econ. 1998, 49, 1-15.

20. Arrow, K.; Solow, R.; Portney, P.R.; Leamer, E.E.; Radner, R.; Schuman, H. Report of the NOAA panel on contingent valuation. Fed. Regist. 1993, 58, 4601-4614.

21. Portney, P.R. The contingent valuation debate: Why economists should care. J. Econ. Perspect. 1994, 8, 3-17.

22. Hanemann, M.; Loomis, J.; Kanninen, B. Statistical efficiency of double-bounded dichotomous choice contingent valuation. Am. J. Agric. Econ. 1991, 73, 1255-1263.

23. Reaves, D.W.; Kramer, R.A. Valuing the Endangered Red Cockaded Woodpecker and Its Habitat: A Comparison of Contingent Valuation Elicitation Techniques and a Test For Embedding; Paper presented at the Association of Environmental and Resource Economists Summer Workshop; AERE: San Diego, CA, USA, August 1994.

24. Bowker, J.M.; Stoll, J.R. Use of dichotomous choice nonmarket methods to value the whooping crane resource. Am. J. Agric. Econ. 1988, 70, 372-381.

25. Tisdell, C.; Wilson, C.; Nantha, H.S. Policies for saving a rare Australian glider: Economics and ecology. Biol. Conserv. 2005, 123, 237-248.

26. Loomis, J.; Ekstrand, E. Economic benefits of critical habitat for the Mexican spotted owl: A scope test using a multiple-bounded contingent valuation survey. J. Agric. Resour. Econ. 1997, 22, 356-366.

27. Bennett, J.; Blamey, R. The Choice Modelling Approach to Environmental Valuation; Edward Elgar Publishing: Cheltenham, UK, 2001.

28. Carson, R.T. Contingent Valuation: A User's Guide; ACS: Washington, DC, USA, 2000.

29. Lancaster, K.J. A new approach to consumer theory. J. Political Econ. 1966, 74, 132-157.

30. Manski, C.F. The structure of random utility models. Theory Decis. 1977, 8, 229-254.

31. Thurstone, L.L. A law of comparative judgment. Psychol. Rev. 1927, 34, 273-286.

32. Choi, A.S.; Fielding, K.S. Environmental attitudes as WTP predictors: A case study involving endangered species. Ecol. Econ. 2013, 89, 24-32.

33. Boxall, P.C.; Adamowicz, W.L.; Swait, J.; Williams, M.; Louviere, J. A comparison of stated preference methods for environmental valuation. Ecol. Econ. 1996, 18, 243-253.

34. Bush, G.; Colombo, S.; Hanley, N. Should all choices count? Using the cut-offs approach to edit responses in a choice experiment. Environ. Resour. Econ. 2009, 44, 397-414.

35. Hanley, N.; Wright, R.E.; Koop, G. Modelling recreation demand using choice experiments: Climbing in Scotland. Environ. Resour. Econ. 2002, 22, 449-466.

36. Bonnet, X.; Shine, R.; Lourdais, O. Taxonomic chauvinism. Trends Ecol. Evol. 2002, 17, 1-3.

37. Clark, J.A.; May, R.M. Taxonomic bias in conservation research. Science 2002, 297, 191-192.

38. White, P.C.; Bennett, A.C.; Hayes, E.J. The use of willingness-to-pay approaches in mammal conservation. Mammal Rev. 2001, 31, 151-167.

39. Yao, R.T.; Scarpa, R.; Turner, J.A.; Barnard, T.D.; Rose, J.M.; Palma, J.H.; Harrison, D.R. Valuing biodiversity enhancement in New Zealand's planted forests: Socioeconomic and spatial determinants of willingness-to-pay. Ecol. Econ. 2014, 98, 90-101.

40. Ressurreição, A.; Gibbons, J.; Kaiser, M.; Dentinho, T.P.; Zarzycki, T.; Bentley, C.; Austen, M.; Burdon, D.; Atkins, J.; Santos, R.S.; et al. Different cultures, different values: The role of cultural variation in public's WTP for marine species conservation. Biol. Conserv. 2012, 145, 148-159.

41. Kotchen, M.J.; Reiling, S.D. Estimating and questioning economic values for endangered species: An application and discussion. Endanger. Species Update 1998, 15, 77-83. 
42. Kotchen, M.J.; Reiling, S.D. Environmental attitudes, motivations, and contingent valuation of nonuse values: A case study involving endangered species. Ecol. Econ. 2000, 32, 93-107.

43. Fishbase. System Glossary Entry for Charismatic Species. Available online: http://www.fishbase.org/ glossary / Glossary.php?q=charismatic+species (accessed on 13 November 2017).

44. Kontoleon, A.; Swanson, T. The willingness to pay for property rights for the giant panda: Can a charismatic species be an instrument for nature conservation? Land Econ. 2003, 79, 483-499.

45. Ducarme, F.; Luque, G.M.; Courchamp, F. What are "charismatic species" for conservation biologists. BioSci. Master Rev. 2013, 10, 1-8.

46. Martín-López, B.; Montes, C.; Benayas, J. The non-economic motives behind the willingness to pay for biodiversity conservation. Biol. Conserv. 2007, 139, 67-82.

47. Metrick, A.; Weitzman, M.L. Patterns of behavior in endangered species preservation. Land Econ. 1996, 72, $1-16$.

48. Tisdell, C.; Nantha, H.S. Comparison of funding and demand for the conservation of the charismatic koala with those for the critically endangered wombat Lasiorhinus krefftii. In Vertebrate Conservation and Biodiversity; Springer: Berlin, Germany, 2006; pp. 435-455.

49. Colléony, A.; Clayton, S.; Couvet, D.; Saint Jalme, M.; Prévot, A.C. Human preferences for species conservation: Animal charisma trumps endangered status. Biol. Conserv. 2017, 206, 263-269.

50. Tisdell, C.; Nantha, H.S.; Wilson, C. Endangerment and likeability of wildlife species: How important are they for payments proposed for conservation? Ecol. Econ. 2007, 60, 627-633.

51. Tkac, J. Award-Winning Undergraduate Paper: The Effects of Information on Willingness-To-Pay Values of Endangered Species. Am. J. Agric. Econ. 1998, 80, 1214-1220.

52. Bandara, R.; Tisdell, C. Changing abundance of elephants and willingness to pay for their conservation. J. Environ. Manag. 2005, 76, 47-59.

53. Pandit, R.; Subroy, V.; Garnett, S.T.; Zander, K.K.; Pannell, D. A Review of Non-Market Valuation Studies of Threatened Species and Ecological Communities; Report to the National Environmental Science Programme; Department of the Environment: Canberra, Australia, 18 December 2015.

54. US Inflation Calculator. Consumer Price Index Data from 1913 to 2017. Available online: http:/ / www.usinflationcalculator.com/inflation/consumer-price-index-and-annual-percent-changesfrom-1913-to-2008/ (accessed on 16 January 2018).

55. Decker, K.A.; Watson, P. Estimating willingness to pay for a threatened species within a threatened ecosystem. J. Environ. Plan. Manag. 2017, 60, 1347-1365.

56. Bandara, R.; Tisdell, C. The net benefit of saving the Asian elephant: A policy and contingent valuation study. Ecol. Econ. 2004, 48, 93-107.

57. Forbes, K.; Boxall, P.C.; Adamowicz, W.L.; De Maio Sukic, A. Recovering Pacific rockfish at risk: The economic valuation of management actions. Front. Mar. Sci. 2015, 2, 71, doi:10.3389/fmars.2015.00071.

58. Zander, K.K.; Signorello, G.; De Salvo, M.; Gandini, G.; Drucker, A.G. Assessing the total economic value of threatened livestock breeds in Italy: Implications for conservation policy. Ecol. Econ. 2013, 93, 219-229.

59. Jakobsson, K.M.; Dragun, A.K. The worth of a possum: Valuing species with the contingent valuation method. Environ. Resour. Econ. 2001, 19, 211-227.

60. Kontogianni, A.; Tourkolias, C.; Machleras, A.; Skourtos, M. Service providing units, existence values and the valuation of endangered species: A methodological test. Ecol. Econ. 2012, 79, 97-104.

61. Boyle, K.J.; Poe, G.L.; Bergstrom, J.C. What do we know about groundwater values? Preliminary implications from a meta analysis of contingent-valuation studies. Am. J. Agric. Econ. 1994, 76, 1055-1061.

62. Poufoun, J.N.; Abildtrup, J.; Sonwa, D.J.; Delacote, P. The value of endangered forest elephants to local communities in a transboundary conservation landscape. Ecol. Econ. 2016, 126, 70-86.

63. Swanson, C.S. Economics of Non-Game Management: Bald Eagles on the Skagit River Bald Eagle Natural Area, Washington. Ph.D. Thesis, The Ohio State University, Columbus, OH, USA, 1993.

64. Stevens, T.H.; Echeverria, J.; Glass, R.J.; Hager, T.; More, T.A. Measuring the existence value of wildlife: What do CVM estimates really show? Land Econ. 1991, 67, 390-400.

65. Baral, N.; Gautam, R.; Timilsina, N.; Bhat, M.G. Conservation implications of contingent valuation of critically endangered white-rumped vulture Gyps bengalensis in South Asia. Int. J. Biodivers. Sci. Manag. 2007, 3, 145-156. 
66. Bell, K.P.; Huppert, D.; Johnson, R.L. Willingness to pay for local coho salmon enhancement in coastal communities. Mar. Resour. Econ. 2003, 18, 15-31.

67. Berrens, R.P.; Ganderton, P.; Silva, C.L. Valuing the protection of minimum instream flows in New Mexico. J. Agric. Resour. Econ. 1996, 21, 294-308.

68. Boyle, K.J.; Bishop, R.C. Valuing wildlife in benefit-cost analyses: A case study involving endangered species. Water Resour. Res. 1987, 23, 943-950.

69. Chambers, C.M.; Whitehead, J.C. A contingent valuation estimate of the benefits of wolves in Minnesota. Environ. Resour. Econ. 2003, 26, 249-267.

70. Giraud, K.; Turcin, B.; Loomis, J.; Cooper, J. Economic benefit of the protection program for the Steller sea lion. Mar. Policy 2002, 26, 451-458.

71. Haqen, D.A.; Vincent, J.W.; Welle, P.G. Benefits of preserving old-growth forests and the spotted owl. Contemp. Econ. Policy 1992, 10, 13-26.

72. Han, S.Y.; Lee, C.K. Estimating the value of preserving the Manchurian black bear using the contingent valuation method. Scand. J. For. Res. 2008, 23, 458-465.

73. Jin, J.; Indab, A.; Nabangchang, O.; Thuy, T.D.; Harder, D.; Subade, R.F. Valuing marine turtle conservation: A cross-country study in Asian cities. Ecol. Econ. 2010, 69, 2020-2026.

74. Jin, J.; Wang, Z.; Liu, X. Valuing black-faced spoonbill conservation in Macao: A policy and contingent valuation study. Ecol. Econ. 2008, 68, 328-335.

75. Kim, J.Y.; Mjelde, J.W.; Kim, T.K.; Lee, C.K.; Ahn, K.M. Comparing willingness-to-pay between residents and non-residents when correcting hypothetical bias: Case of endangered spotted seal in South Korea. Ecol. Econ. 2012, 78, 123-131.

76. Thuy, T.D. WTP for Conservation of Vietnamese Rhino; Technical Report; Research Report; Economy and Environment Program for Southeast Asia (EEPSEA): Singapore, 2007; 40p.

77. White, P.C.; Gregory, K.W.; Lindley, P.J.; Richards, G. Economic values of threatened mammals in Britain: A case study of the otter Lutra lutra and the water vole Arvicola terrestris. Biol. Conserv. 1997, 82, 345-354.

78. Whitehead, J.C. Ex ante willingness to pay with supply and demand uncertainty: Implications for valuing a sea turtle protection programme. Appl. Econ. 1992, 24, 981-988.

79. Matsiori, S.; Stamkopoulos, Z.; Aggelopoulos, S.; Soutsas, K.; Vafidis, D. Social values of biodiversity conservation for Mediterranean monk seal (Monachus monachus). Afr. J. Agric. Res. 2013, 8, 2022-2026.

80. Giraud, K.; Loomis, J.B.; Johnson, R. Internal and external scope in willingness-to-pay estimates for threatened and endangered wildlife. J. Environ. Manag. 1999, 56, 221-229.

81. Loomis, J.B.; Larson, D.M. Total economic values of increasing gray whale populations: Results from a contingent valuation survey of visitors and households. Mar. Resour. Econ. 1994, 9, 275-286.

82. Tisdell, C.; Swarna Nantha, H.; Wilson, C. Public Valuation of and Attitudes Towards the Conservation and Use of the Hawksbill Turtle: An Australian Case Study; The University of Queensland School of Economics: St Lucia, Australia, 2005.

83. Langford, I.H.; Kontogianni, A.; Skourtos, M.S.; Georgiou, S.; Bateman, I.J. Multivariate mixed models for open-ended contingent valuation data: Willingness to pay for conservation of monk seals. Environ. Resour. Econ. 1998, 12, 443-456.

84. Stithou, M.; Scarpa, R. Collective versus voluntary payment in contingent valuation for the conservation of marine biodiversity: An exploratory study from Zakynthos, Greece. Ocean Coast. Manag. 2012, 56, 1-9.

85. Hageman, R.K. Valuing Marine Mammal Populations: Benefit Valuations in A Multi-Species Ecosystem; National Marine Fisheries Service, Southwest Fisheries Center: La Jolla, CA, USA, 1985.

86. Rathnayake, R.M.W. "Turtle watching": A strategy for endangered marine turtle conservation through community participation in Sri Lanka. Ocean Coast. Manag. 2016, 119, 199-207.

87. Ma, K.; Liu, D.; Wei, R.; Zhang, G.; Xie, H.; Huang, Y.; Li, D.; Zhang, H.; Xu, H. Giant panda reintroduction: Factors affecting public support. Biodivers. Conserv. 2016, 25, 2987-3004.

88. Indab, A.L. Willingness to pay for whale shark conservation in Sorsogon, Philippines. In Marine and Coastal Ecosystem Valuation, Institutions, and Policy in Southeast Asia; Springer: Berlin, Germany, 2016; pp. 93-128.

89. Zander, K.K.; Pang, S.T.; Jinam, C.; Tuen, A.A.; Garnett, S.T. Wild and valuable? Tourist values for orang-utan conservation in Sarawak. Conserv. Soc. 2014, 12, 27-42.

90. Tisdell, C.; Wilson, C. Information, wildlife valuation, conservation: Experiments and policy. Contemp. Econ. Policy 2006, 24, 144-159. 
91. Rubin, J.; Helfand, G.; Loomis, J. A benefit-cost analysis of the northern spotted owl. J. For. (USA) 1991, 89, 25-30.

92. Wallmo, K.; Lew, D.K. Valuing improvements to threatened and endangered marine species: An application of stated preference choice experiments. J. Environ. Manag. 2011, 92, 1793-1801.

93. Rudd, M.A. National values for regional aquatic species at risk in Canada. Endanger. Species Res. 2009, 6, 239-249.

94. Han, S.Y.; Lee, C.K.; Mjelde, J.W.; Kim, T.K. Choice-experiment valuation of management alternatives for reintroduction of the endangered mountain goral in Woraksan National Park, South Korea. Scand. J. For. Res. 2010, 25, 534-543.

95. Wallmo, K.; Lew, D.K. Public willingness to pay for recovering and downlisting threatened and endangered marine species. Conserv. Biol. 2012, 26, 830-839.

96. Ninan, K.; Sathyapalan, J. The economics of biodiversity conservation: A study of a coffee growing region in the Western Ghats of India. Ecol. Econ. 2005, 55, 61-72.

97. Boxall, P.; Adamowicz, W.; Olar, M.; West, G.; Cantin, G. Analysis of the economic benefits associated with the recovery of threatened marine mammal species in the Canadian St. Lawrence Estuary. Mar. Policy 2012, 36, 189-197.

98. Kahneman, D.; Knetsch, J.L. Valuing public goods: The purchase of moral satisfaction. J. Environ. Econ. Manag. 1992, 22, 57-70.

(c) 2018 by the authors. Licensee MDPI, Basel, Switzerland. This article is an open access article distributed under the terms and conditions of the Creative Commons Attribution (CC BY) license (http://creativecommons.org/licenses/by/4.0/). 